\title{
Devolución de comisiones: ¿Cuánto cuesta la equidad?
}

Fernando López

Profesor de Finanzas, Universidad Alberto Hurtado

Andrés Morgado

Ayudante de investigación, Universidad Alberto Hurtado

Este estudio analiza el impacto que tendría una reforma al sistema de pensiones que obligue a las AFP a devolver las comisiones cobradas en los periodos en que los fondos que administran tengan rentabilidades negativas. Los resultados muestran que esta medida inducirá a las administradoras a implementar estrategias de inversión más conservadoras y esto reducirá el valor esperado de las pensiones futuras. El análisis muestra que mientras mayor sea el periodo considerado para calcular la rentabilidad de referencia para la devolución, menor será el impacto de esta medida. Sin embargo, incluso considerando un periodo de 5 años, los Fondos A y B se verían afectados.

L un discurso en el que anunció una serie de medidas orientadas a mejorar el sistema de pensiones. Estas iniciativas apuntan a mejorar el nivel de las pensiones, aumentar la competencia y darle mayor legitimidad al sistema. Entre las medidas anunciadas, una de las más innovadoras plantea que las AFP devuelvan las comisiones cobradas a los afiliados en periodos en que los fondos de pensiones tengan rentabilidades negativas. Porque, como dijo la Presidenta, "las pérdidas en los fondos de los trabajadores no pueden ser un negocio para nadie", esta medida apunta a promover la equidad del sistema de pensiones. De esta manera, el Gobierno aborda el descontento ciudadano asociado al hecho de que las AFP alcanzan utilidades "excesivas", incluso cuando los trabajadores pierden. En este contexto, el objetivo de este artículo es analizar la manera en que esta medida afecta los incentivos de las administradoras para invertir los ahorros previsionales y su posible impacto en las pensiones. 
Descontento con el sistema de pensiones y las utilidades de las AFP

El sistema de pensiones chileno tiene indignada a una parte importante de la población. Uno de los principales motivos de este descontento es la convivencia de bajas pensiones, altas ganancias de las AFP y privilegios de un grupo reducido de personas que se han hecho públicos en los últimos meses. Una de las principales causas del descontento de la ciudadanía con las AFP son sus utilidades que son consideradas excesivas. Desafortunadamente, no hay estudios formales que aborden este tema. Lo mejor que se ha hecho hasta la fecha es comparar las rentabilidades de las AFP con las alcanzadas por la industria bancaria, lo cual nos da una idea general del "posible" exceso o, al menos, de la causa del descontento.

En efecto, la rentabilidad sobre patrimonio promedio de las AFP en el período $1991-2015$ fue $27,7 \%$, un $73 \%$ mayor al $16 \%$ alcanzado por la banca en el mismo periodo. Para ilustrar esta cifra, por cada $\$ 100$ invertidos, la industria de AFP ha obtenido una ganancia de $\$ 27,7$ anuales después de impuestos. Con este ritmo de ganancias, su patrimonio se duplica en menos de cuatro años.

Desde un punto de vista económico, las ganancias elevadas y sostenidas en el tiempo son un síntoma de que el mercado no funciona de manera competitiva. Por esta razón, la falta de competencia de la industria fue uno de los temas centrales abordados tanto por la Comisión Marcel, que dio origen a la reforma de 2008, así como por la Comisión Bravo.

\section{Devolución de comisiones}

Para entender el impacto de la iniciativa, calculamos el número de meses en que las AFP hubiesen tenido que devolver las comisiones a los cotizantes si esta hubiese estado vigente en el periodo 2007-2015. Los principales resultados están en la Figura 1. Se aprecia que la frecuencia de devolución de comisiones depende del riesgo del fondo y del periodo considerado para calcular su rentabilidad. Por una parte, se observa que el número de meses en que las AFP tendrían que devolver las comisiones cobradas aumenta con el riesgo de los fondos. Adicionalmente, el número de meses en que los cotizantes hubiesen recibido la devolución de sus comisiones disminuye con el periodo considerado para calcular la rentabilidad. En efecto, para el caso del Fondo E, si el periodo considerado para calcular la rentabilidad hubiese sido igual a 24 meses, entonces las AFP no hubiesen devuelto comisiones en todo el periodo por los recursos invertidos dicho fondo. Con un periodo de referencia de 36 meses, los Fondos D y E tampoco hubiesen devuelto comisiones. Sin embargo, incluso considerando un periodo de 5 años, de todas maneras los Fondos A y B hubiesen devuelto comisiones un $22 \%$ y $8 \%$ de los periodos, respectivamente.

\section{Impacto de la devolución de comisiones}

La regulación de inversiones de los fondos de pensiones establece límites máximos y mínimos para la inversión en activos de renta variable, que generalmente son considerados más riesgosos. Como se aprecia en la Tabla 1, estos límites dan espacio a las AFP para seleccionar el nivel de riesgo de los fondos. Por ejemplo, minimizando el nivel de inversión en renta variable,

\section{Figura 1}

Devolución de comisiones según fondo de pensión y periodo de referencia para el cálculo de la rentabilidad (agosto 2007 -diciembre 2015)

El eje vertical muestra el número de meses en que las AFP hubiesen tenido que devolver las comisiones a sus afiliados en el periodo agosto 2007 - diciembre 2015. El eje horizontal muestra el periodo de referencia para el cálculo de la rentabilidad con la cual se determinaría si la AFP tiene que devolver o no las comisiones a los cotizantes.

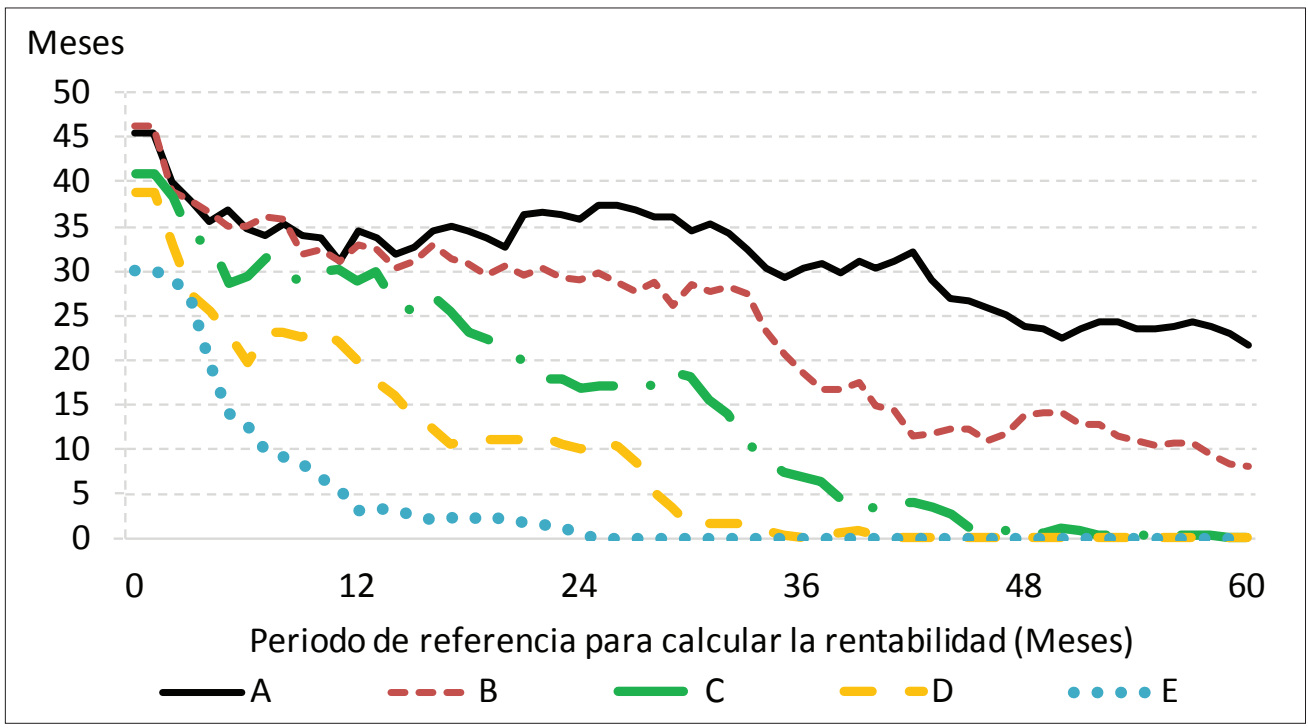


el fondo A podría quedar en el límite máximo de renta variable del Fondo $C$, que coincide con el limite mínimo del Fondo A. También se podría reducir el nivel de renta variable del Fondo $B$ al nivel del Fondo $C$, del $C$ al $D$ y del $D$ al E. De acuerdo a los resultados de la Figura 1, las AFP tendrían la opción de reducir la probabilidad de devolución de comisiones disminuyendo el nivel de riesgo de los fondos de pensiones.
Al reducir el nivel de riesgo de sus inversiones, la rentabilidad esperada de los fondos de pensiones será menor. De esta manera, la principal consecuencia indeseada de la medida es un efecto negativo en pensiones que ya son bajas. Para ilustrar la magnitud del impacto, basta considerar que si el fondo de una persona que se jubiló en diciembre de 2015 hubiese tenido una rentabilidad de un $1 \%$ mayor durante sus últimos diez años de cotización, su pensión seria un 10\% mayor. La Figura 2 muestra la rentabilidad promedio histórica de los fondos de pensiones. Para ilustrar la diferencia, basta considerar que si las AFP hubiesen reducido el riesgo del Fondo A al nivel del Fondo B, la rentabilidad promedio hubiese caído en 1,12\% anual. Esta rentabilidad hubiese caído en 1,54\% si el nivel de riesgo del Fondo $A$ hubiese disminuido al nivel del fondo $C$.
Tabla 1

Límites de inversión en renta variable

\begin{tabular}{ccc} 
& Máximo & Mínimo \\
\hline A & $80 \%$ & $40 \%$ \\
B & $60 \%$ & $25 \%$ \\
C & $40 \%$ & $15 \%$ \\
D & $20 \%$ & $5 \%$ \\
E & $5 \%$ & $0 \%$
\end{tabular}

\section{Conclusión}

Este estudio analiza el posible impacto en la estrategia de inversión de las AFP y la rentabilidad de los fondos de pensiones de una medida que las obliga a devolver las comisiones cobradas en los periodos en que los fondos tengan rentabilidades negativas. Los resultados muestran que la iniciativa reducirá los incentivos de las AFP para tomar riesgos

\section{Figura 2}

Rentabilidad multifondos 2002-2015

(Promedio ajustado por UF) $y$, por consiguiente, la rentabilidad esperada de los fondos de pensiones será menor. Una simulación histórica muestra que en el periodo 2007-2015 el desincentivo a tomar riesgos podría reducir la rentabilidad de los fondos en más de un $1 \%$. Si esta situación se mantiene por un periodo de 10 años, el impacto adverso en la pensión seria mayor a un $10 \%$. ¿Es tan grande el descontento como para pagar un precio tan alto?

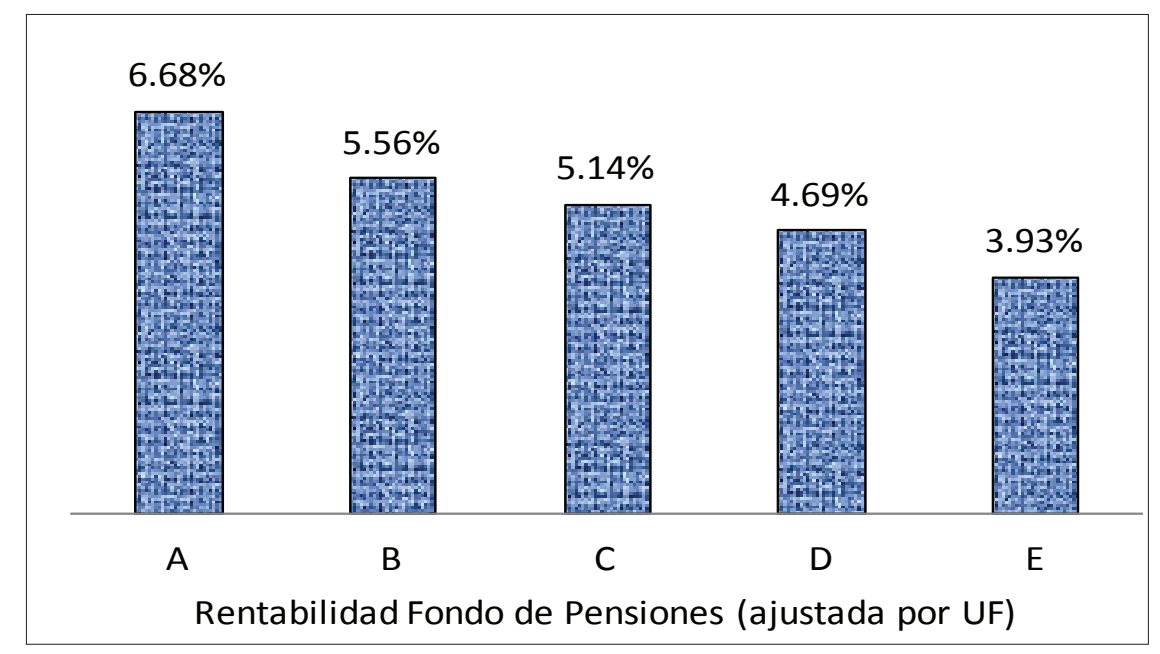

Fuente: Superintendencia de Pensiones. 


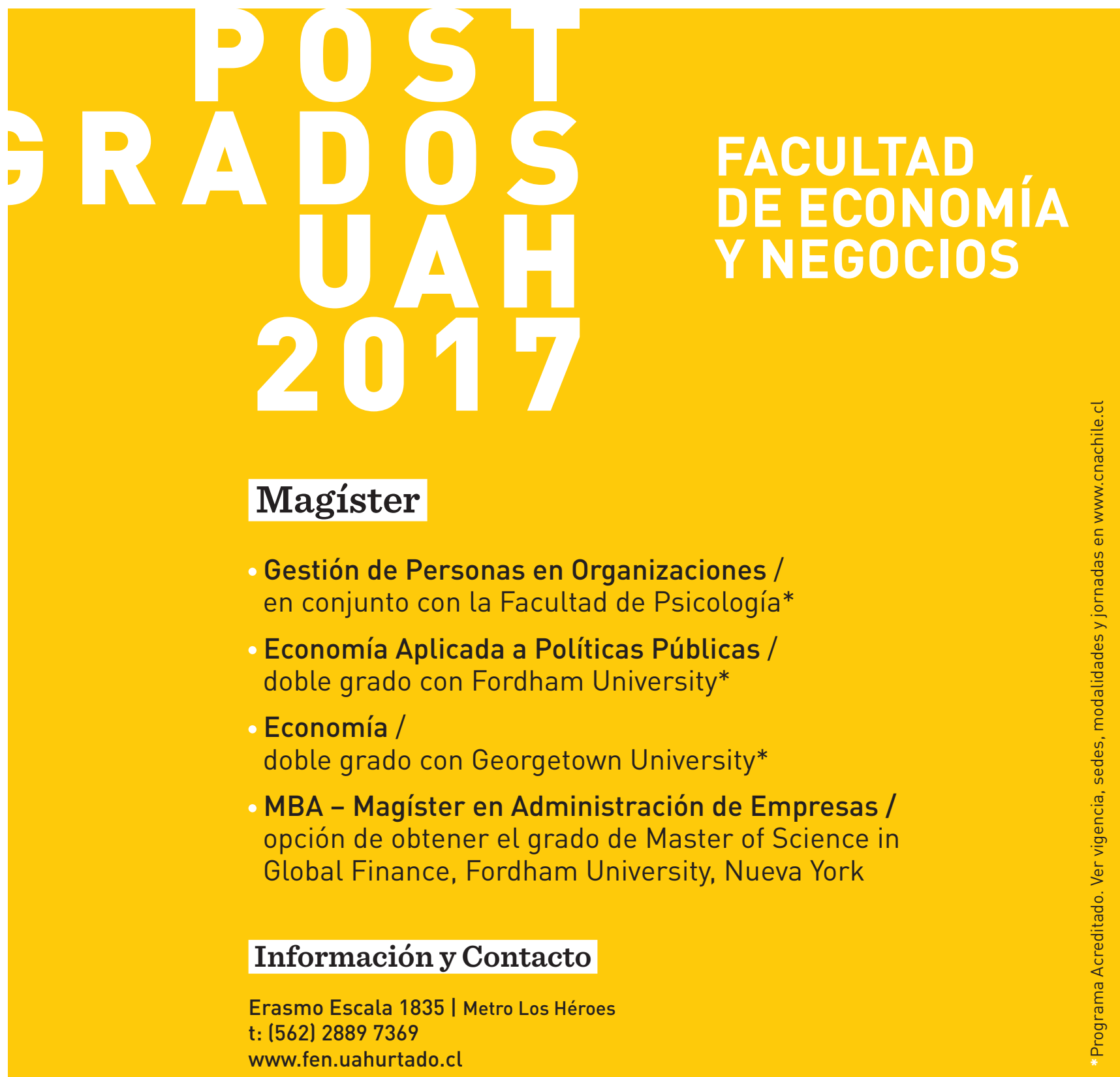

